\title{
How reinforcement context affects temporal production and categorization
}

\author{
JONATHAN J. BEAM, PETER R. KILLEEN, and LEWIS A. BIZO \\ Arizona State University, Tempe, Arizona \\ and \\ J. GREGOR FETTERMAN \\ Indiana University-Purdue University, Indianapolis, Indiana
}

\begin{abstract}
The behavioral theory of timing assumes that timing is governed by a pacemaker whose pulses move organisms from one state to the next, and that the speed of the pacemaker covaries with the rate of reinforcement in the experimental context. The goal of the present experiments was to clarify just what constitutes that context. In Experiment 1, pigeons responded on signaled fixed-interval 20-sec and 40sec schedules of food reinforcement that were presented randomly within sessions (alternating condition) or between sessions (isolated condition). In Experiment 2, pigeons categorized the duration of a short or a long set of intervals in the alternating or the isolated condition. Performance in both experiments was under strong control by the signals, with scalar timing between long and short sets, but no significant differences between the alternating and isolated conditions. The context of reinforcement that determines pacemaker period can thus be specific to a particular timing task and signal.
\end{abstract}

Weber's law, a statement of the relativity of perception, is ubiquitously found to govern the discriminability of intensive or extended stimuli. This is also true for the perception of elapsed time intervals, with exception at the very shortest intervals (Allan \& Kristofferson, 1974). Any theory of temporal perception must have Weber's law as a theorem, or it is a nonstarter. Most timing theories involve one or more pacemakers that generate pulses and a counter that registers them; however, in some of the theories, the role of one or the other of the components may be central, and in others, only nominal. Killeen and Weiss (1987) provide a framework for analyzing such systems, showing that most basic pacemaker-counter systems predict a generalized Weber's law:

$$
\sigma_{t}^{2}=(w t)^{2}+p t+c^{2}
$$

where $\sigma_{t}^{2}$ is the variance in the estimates of an interval of duration $t$. The parameter $w$ is the Weber fraction and represents scalar sources of variance (caused, for instance, by variance in the counter), $p$ is the Poisson fraction and represents linear sources of variance (caused, for instance, by variance in the pacemaker), and $c$ represents constant

The research was supported by NSF Grants IBN 9408022 and NIMH K05 MH01293 to P.R. Killeen and BNS 9021562 and IBN 9407527 to J. G. Fetterman. Experiment 1 was based on a thesis submitted to Arizona State University by J. J. Beam in partial fulfillment of the requirements for the MA degree. Experiment 2 was conducted at IUPUI. L. A. Bizo is now at the Department of Psychology, University of Southampton, Highfield, Southampton, UK S017 1BJ. Correspondence should be addressed to J. G. Fetterman, Department of Psychology, IUPUI, 402 N. Blackford St., Indianapolis, IN 46202-3275 (e-mail: gfetter@iupui.edu). sources of variance (caused, for instance, by error in starting or stopping the counter, as with intervals that end between counts).

Two major theories of timing derive Weber's law in two different ways: Scalar expectancy theory (SET; e.g., Gibbon, 1986; Gibbon \& Church, 1984) has the variance arise from proportional error in the counter $(w)$. Because the number of counts is proportional to the length of the interval to be timed, that proportional variability is propagated onto temporal estimates, yielding Weber's law. The speed of the pacemaker is assumed to be so fast that its contribution to overall error is insignificant (Gibbon, 1992) - that is, over most of its range, $(w t)^{2}$ dominates $p t$ in Equation 1.

In the behavioral theory of timing (BeT; e.g., Killeen \& Fetterman, 1988, 1993), the recurrent pulses move the animal into a state that has been conditioned as a cue for a "short" or "long" response, which it will make given the opportunity. It takes $n$ pulses to do this, with $n$ being called the criterion. The criterion state is achieved at a time $t=$ $n \tau$, with variance $\sigma^{2}=n \tau^{2}$, where $t$ is the average period between pulses. For the animal's criterial state to correspond with real time, either the criterion or the period of the pacemaker must change proportionately with changes in $t$. SET has the criterion change; BeT has the period change: $\tau=k t$. In the latter case, it follows that $\sigma^{2}=n(k t)^{2}$. This is Weber's law. It corresponds to Equation 1 with $w$ and $c$ equal to zero, and $p=k n \tau$. Nonzero values for $w$ and $c$ are also possible, but, for the sake of parsimony, they have not generally been exploited by BeT. Increasing evidence suggests that the speed of the pacemaker is bounded both from above and from below, which would predict a failure of Weber's law at the extremes of the range. 
Changes in pacemaker speed are assumed to be mediated by changes in the arousal level of the organism, which is driven not only by rate of reinforcement (Gibbon, 1995; Killeen, 1975, 1979) but also by drugs (Meck, 1983; Meck \& Church, 1987), circadian rhythms (Shurtleff, Raslear, \& Simmons, 1990), body temperature (Wearden \& PentonVoak, 1995), and other arousing stimuli (Penton-Voak, Edwards, Percival, \& Wearden, 1996). These changes in arousal may become conditioned to environmental stimuli (e.g., Morgan, Killeen, \& Fetterman, 1993; Roberts \& Holder, 1985).

It would seem a simple matter to determine the speed of the pacemaker and whether it is fixed or variable, since that is a central point of contention between BeT and SET. However, since this hypothetical construct is not directly observable, it must be viewed through the
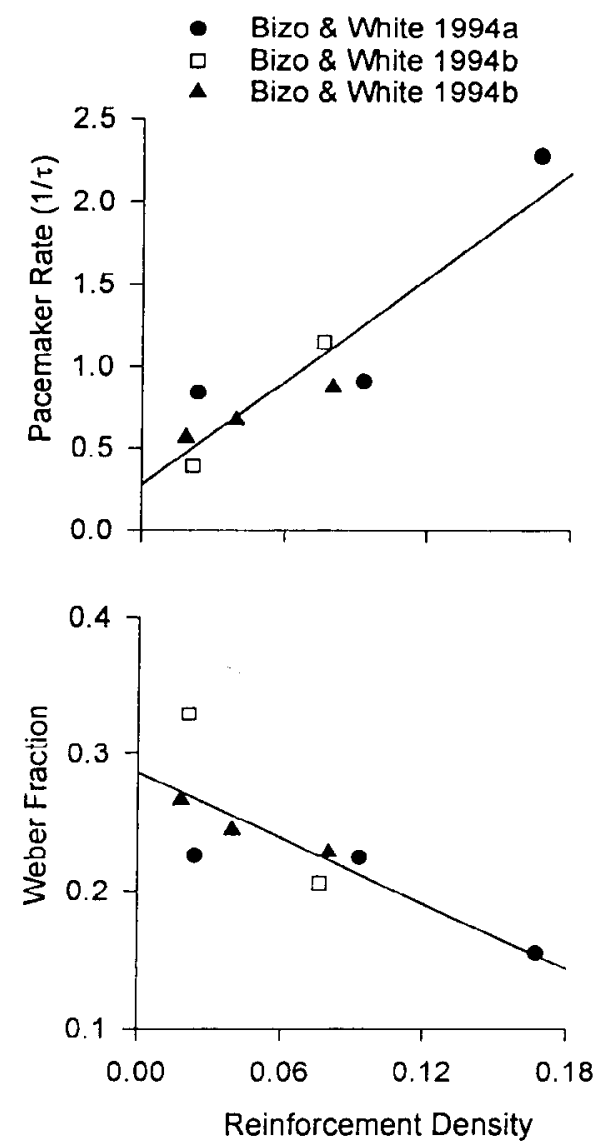

Figure 1. Top panel: Speed of pacemaker $(1 / \tau$ pulses per sec) as a function of reinforcement density (rate of reinforcement times amount of reinforcement). The data are from experiments that varied rate of reinforcement (disks), duration of reinforcement (squares), and intertrial interval (triangles). Bottom panel: The Weber fraction $w(=\sigma / \mu)$ from the same experiments. From "Timing with controlled reinforcer density: Implications for models of timing," by L. A. Bizo \& K. G. White, 1997, Journal of Experimental Psychology: Animal Behavior Processes, 23, p. 46. Copyright 1997 by The American Psychological Association. Reprinted with permission. speculum of theory. BeT estimates the period of the pacemaker $(\tau)$ and the criterial number of pulses $(n)$ by fitting a gamma distribution to the data (see Equation 2, below). This analysis indicates that changes in pacemaker speed occur, just as predicted, when rate of reinforcement is varied (e.g., Bizo \& White, 1994a; Fetterman \& Killeen, 1991, 1995; MacEwen \& Killeen, 1991). However, the inferred changes in pacemaker speed have been less than proportional to reinforcement rate (see, e.g., Killeen, Fetterman, \& Bizo, 1997). The relation is linear, rather than strictly proportional (Figure 1), because arousal levels of zero are atypical of conscious organisms: Alternate sources of reinforcement, or the search for them, make the relation between extrinsic reinforcement and arousal level linear, rather than proportional. This is the same kind of observation that led Herrnstein (1970) to invoke $R_{O}$, alternate sources of reinforcement in an organism's environment, to explain the nonlinear relation between response rate and reinforcement rate on many schedules of reinforcement.

Not only does such concurrent unscheduled reinforcement affect arousal level, so also may the presence (or absence) of reinforcers in alternative contexts. This potential change in arousal level may in turn affect the speed of the pacemaker. For example, Fetterman and Killeen (1991) found little effect of the length intertrial interval (ITI) on pacemaker speeds, but Bizo and White (1994b) did find an effect, and Wilkie and Symons (1988) found an effect of free reinforcers delivered during the ITI

Haight and Killeen (1991) shifted rate of reinforcement in one component of a multiple schedule and found correlated shifts in adjunctive behaviors consistent with partial control by the other component (induction). Roberts (1981) trained rats on a modified discrete trial fixedinterval (FI) schedule known as the peak procedure (Catania, 1970). Two criterial times (FI 20-sec and FI 40-sec) signaled by different stimuli (light and sound) were used. If there were perfect isolation of the contexts, both BeT and SET would predict scalar timing (2-to-1 ratios of standard deviations). If there were no isolation, BeT would predict a $\sqrt{2}$ ratio. Killeen and Fetterman (1988) reanalyzed Roberts's data and found that the results were midway between the two alternatives. Perhaps this was due to less-than-perfect stimulus control. In the present experiments, we sought to further determine the conditions under which signaled periods of reinforcement within the same experimental chamber could remain independent, by varying the proximity of those periods within or between sessions.

\section{EXPERIMENT 1}

In Experiment 1, pigeons were trained to estimate different interreinforcer intervals under two variations of the peak procedure. In one set of (isolated) conditions, subjects were exposed to one interreinforcer interval for an extended number of sessions and were subsequently exposed to a second interreinforcer interval for a compara- 
ble number of sessions. In another (alternating) condition, the interreinforcer intervals alternated randomly within sessions, and different key color stimuli signaled the value of the prevailing interval. To the extent that arousal (and pacemaker speed) can come under close control of the stimuli, as we hoped these conditions would establish, the distributions of responding in the two conditions were expected to be identical for equal FI values.

\section{Method}

\section{Subjects}

Four adult male homing pigeons (Columba livia) served as subjects. All subjects were experimentally naive. The pigeons had free access to water and grit and were housed individually in a room with a 12:12-h day:night cycle, with the day cycle beginning at 8 a.m. Each pigeon was weighed before each session and was excluded from a session if its weight exceeded $10 \mathrm{~g}$ of its $80 \%$ ad-lib weight. When required, supplementary food, consisting of fortified mixed grain, was given at the end of each day.

\section{Apparatus}

A single $31 \mathrm{~cm}$ wide $\times 35 \mathrm{~cm}$ deep $\times 34 \mathrm{~cm}$ high LVE (Laurel, $\mathrm{MD}$ ) operant chamber was used. An intelligence panel mounted on the front wall contained two Plexiglas keys $2 \mathrm{~cm}$ in diameter located $19 \mathrm{~cm}$ from the chamber floor and positioned $11 \mathrm{~cm}$ apart. The left key could be illuminated by a red light, and the right key by a green light, and both by white lights. Each key required at least $0.2 \mathrm{~N}$ for activation. A houselight located $15 \mathrm{~cm}$ from the side wall and $2 \mathrm{~cm}$ from the chamber ceiling could be illuminated with white light. A grain hopper located $7 \mathrm{~cm}$ above the chamber floor could provide 3-sec access to milo grain. White noise was delivered into the chamber through a small speaker; additional masking was provided by a ventilation fan mounted on the wall opposite the interface panel. Experimental events were controlled and recorded by a PC clone

\section{Procedure}

Basic training. The pigeons were trained to eat from a raised food hopper. They were then autoshaped to peck at a white key that was randomly varied from left to right positions on the front wall. After responding was established, the pigeons were trained on a fixed-ratio 1 (FR 1) schedule of reinforcement. In this condition, one of the keys was randomly selected and illuminated with white light; a single response to it resulted in reinforcement (3-sec access to milo grain), followed by the random re-illumination of one of the two keys. This continued until 50 reinforcers had been collected in each of three sessions. Thereafter, the pigeons were exposed to the following ABA design, with the number of sessions in each condition given in Table 1. Sessions were conducted 6 days per week, with 60 reinforcements per session. During reinforcement, the hopper was illuminated with a small bulb within the hopper, while the houselight and keylights were extinguished.

Table 1

Summary of Conditions and the Number of Sessions Completed by Each Pigeon in Each Condition of Experiment 1

\begin{tabular}{lcccc}
\hline & \multicolumn{4}{c}{ Pigeon } \\
\cline { 2 - 5 } Condition & 2 & 6 & 10 & 16 \\
\hline 1 (Alternating) & $46(1)$ & $45(1)$ & $46(1)$ & $34(1)$ \\
2 (Isolated) & & & & \\
FI 20 & $19(2)$ & $19(2)$ & $18(3)$ & $16(3)$ \\
FI 40 & $24(3)$ & $19(3)$ & $23(2)$ & $21(2)$ \\
1 (Replication) & $21(4)$ & $19(4)$ & $20(4)$ & $15(4)$ \\
\hline
\end{tabular}

Note-The order of exposure to each condition appears in parentheses.
Condition 1 (alternating). Sessions were initiated by the onset of the houselight. Half of the trials began with the onset of a green light behind the left key, and half began with the onset of a red light behind the right key. Responses to the left (green) key were reinforced according to an FI 20-sec schedule, and responses to the right (red) key were reinforced according to an FI 40-sec schedule. Keylights and the houselight were extinguished at the onset of reinforcement. Both green-key and red-key periods included unreinforced probe trials that lasted three times as long as the FI valuethat is, $60 \mathrm{sec}$ during the FI 20 signal and $120 \mathrm{sec}$ during the FI 40 signal. Twelve probe trials ( 6 during each key-color period) were scheduled in each session, one probe occurring in each block of 5 trials. The order of key illumination was randomized within a session with the constraint that the same key could not be illuminated more than 2 trials in a row. Trials were separated by a $1-\mathrm{sec}$ ITI, during which all lights in the chamber were darkened.

Condition 2 (isolated). This was similar to the first condition except that the FIs were presented separately, as opposed to within sessions. In each phase of this condition, either the left or the right key was illuminated throughout the entire session. During the FI 20 schedule, the left key was illuminated red; during the FI 40 schedule, the right key was illuminated green. Twelve of the 60 trials were probe trials during which responding was in extinction and lasted three times the FI duration. The order of exposure to the FIs was counterbalanced across pigeons.

Condition 3 (replication of Condition 1). The pigeons were returned to the alternating condition. Sessions were initiated by the onset of the houselight. Half of the trials began with the onset of a green light behind the left key, and half began with the onset of a red light behind the right key. Responses to the left (green) key were reinforced according to an FI 20 -sec schedule, and responses to the right (red) key were reinforced according to an FI 40-sec schedule. Both green-key and red-key periods included unreinforced probe trials that lasted three times as long as the FI value - that is, $60 \mathrm{sec}$ during the FI 20 signal and $120 \mathrm{sec}$ during the FI 40 signal. Twelve probe trials ( 6 during each key-color period) were scheduled in each session, one probe occurring in each block of 5 trials. The order of key illumination was randomized within a session with the constraint that the same key could not be illuminated more than 2 trials in a row. Trials were separated by a $1-\mathrm{sec}$ ITI, during which all lights in the chamber were darkened.

\section{Data Analysis}

The number of keypeck responses was tabulated in 2-sec time bins on probe trials. Response rates in each time bin were calculated using data averaged across the last 10 sessions of each condition, across replications of Condition 1 , and across subjects.

Gamma densities (multiplied by a scale factor for response rate) were fitted to the functions relating binned response rates to the time since trial onset. The densities usually accounted for over $98 \%$ of the variance for the distributions of individual subjects (the median coefficient of determination was .985). The key parameters of the gamma distribution are $\tau$ and $n$; the former represents the average time between pulses (the period of the pacemaker, $\tau$ ), and the latter represents the criterial number of pulses required to shift the pigeon into the keypecking state. Accordingly, at any time $t$ through the course of an interval,

$$
p(N(t)=n)=\frac{(t / \tau)^{n} e^{(-t / \tau)}}{\tau n !} \tau>0, n \geq 0 .
$$

Equation 2 gives the probability that the number of pulses at time $t, N(t)$, equals $n$, with the $n$th state correlated with the measured response, such as pecking a key. (Animals may stay in the "peck" state for more than one pulse, but that extra assumption-and parameter-is not necessary for the analysis of these data.) It is sometimes written with the parameter $n-1$ instead of $n$, signifying the number of pulses necessary to exit the state. We may use Equation 2 
to estimate the criterial number of pulses and to find the average time between pulses, $\tau$. These parameters jointly determine the mean and standard deviation of the density (Equation 2); when the gamma density is expressed as Equation 2, these are

$$
\mu=\tau(n+1)
$$

and

$$
\sigma=\tau \sqrt{n+1}
$$

If pacemaker speed remains constant across changes in the interreinforcer interval, either within or across conditions, the subjects can only adapt by changing the criterion $n$; as a consequence, the standard deviation will increase as the square root of the meanPoisson timing (Gibbon, 1977). In general for such a process, the coefficient of variation is $\mathrm{CV}=\sigma / \mu=(n+1)^{-1 / 2}$. Alternatively, if pacemaker period increases with the interval to be timed ( $n$ remaining constant), the standard deviation will increase proportionately with the mean; this is scalar, or Weber timing, for which $\mathrm{CV}=$ $\sigma / \mu=w$. We develop this logic as we report the data, which were represented by gamma densities that minimized the sum of squared deviations between the fitted curves and data.

\section{Results and Discussion}

Equation 2 was fit to the data from individual pigeons. Values of $\mu$ and $\sigma$ may be derived from these using Equations 3 and 4 . The top panel of Figure 2 shows that the average pacemaker periods were the same whether the FI 20 was experienced by itself (black bar) or alternating with the FI 40 (striped bars). The same is the case for the FI 40. This panel answers in the affirmative the central question that motivated this experiment: Can pacemaker speed come under strong stimulus control so as to be a function of local rate of reinforcement, or is it a more organismic variable subject only to the rate of reinforcement in real time?

Figure 2 shows that the data from Condition 1 and its replication (Condition 3 ) were quite similar. There were no significant differences in the values of $\tau$ or the means of the distributions between the original and the replications of the alternating condition $[t(3)=-.414$, all $p \mathrm{~s}>$ $.05]$, nor between the means of the isolated and alternating conditions $[t(3)=-.537$, all $p s>.05]$. These data were therefore pooled and reanalyzed, and the resulting parameters are presented in Table 2 for each pigeon and condition.

The bottom panel of Figure 2 displays the average values of the standard deviations $(\sigma)$ for the various conditions. The ratios of the standard deviations of the FI 20-sec and FI 40-sec components of the isolated and alternating schedules were $2: 1$ in both cases, as predicted by Weber's law. Thus, we have replicated the standard finding of scalar timing.

A summary picture of changes in responding is provided by Figure 3, whose top panel shows the average response rate functions for Conditions 1 and 3 , where the FIs alternated within sessions. Response rates increase and then decrease through time, with the peak of each function near the criterial times of reinforcement $(20-\mathrm{sec}$ and $40-\mathrm{sec}$ ); both functions are positively skewed, which is typical of both peak-procedure data and of the gamma
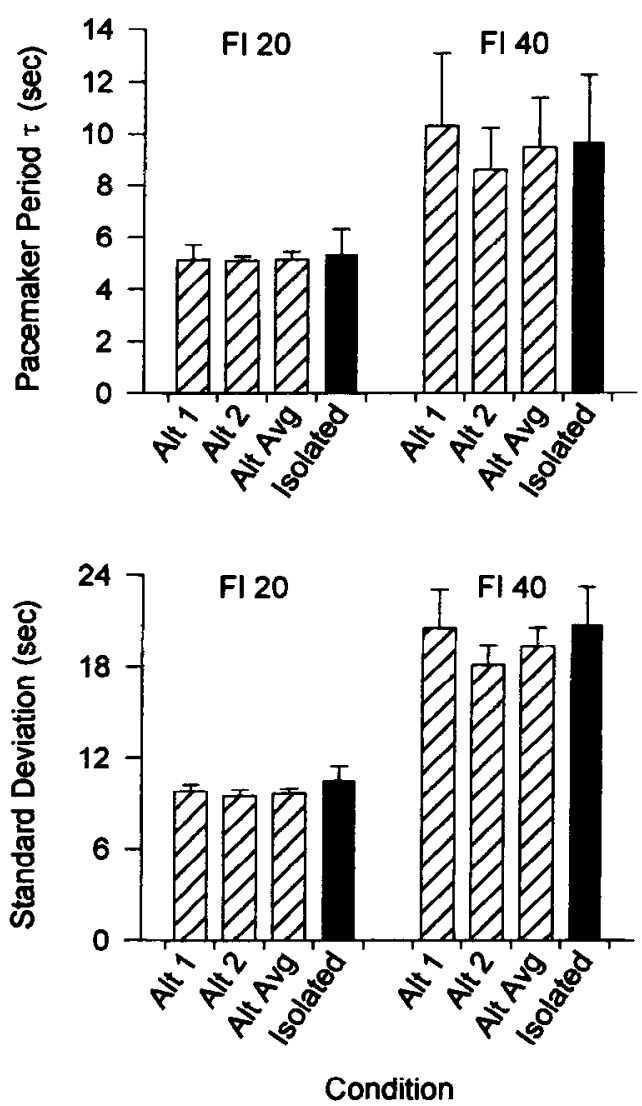

Figure 2. Average pacemaker periods (top panel) and standard deviations (bottom panel) plotted as a function of fixed interval duration for the alternating (light fill) and isolated (dark fill) conditions of Experiment 1. For the alternating (Alt) conditions, data from original (Condition 1), replication (Condition 3), and their average are shown separately.

density function. The bottom panel of Figure 3 shows comparable data from Condition 2 , where the different interreinforcer intervals were presented in separate phases. The response patterns are very similar to those in the top panel. Qualitatively, then, the timing of different durations does not appear to be influenced by the context in which it is accomplished, as long as the context is clearly signaled.

Was Weber's law brought about by proportional changes in $\tau$ ? The recovered values of $\tau$ increased with FI value in both conditions (see the top panel of Figure 2). The ratios of $\tau$ (FI 40/FI 20) were significantly greater than 1.0 for both conditions $[t(3)=4.33$, and $t(3)=4.85$, for Conditions 1 and 2 , respectively, both $p \mathrm{~s}<.05$ ]: Pacemaker period covaried with the interval to be timed, as predicted by BeT, and was thus a significant causal factor in the obtained scalar timing. The sizes of the changes in $\tau$ were similar in both conditions: The ratios of $\tau$ values for the FI 40 -sec to the FI 20 -sec components of the alternating and isolated schedules were 1.84 and 1.81 , respectively, neither significantly differ- 
Table 2

Estimates of Pacemaker Period, $\tau$, and Criterion, $n$

\begin{tabular}{|c|c|c|c|c|c|c|c|c|}
\hline \multirow[b]{3}{*}{$\mathrm{FI}(\mathrm{sec})$} & \multicolumn{8}{|c|}{ Pigeon } \\
\hline & \multicolumn{2}{|c|}{2} & \multicolumn{2}{|c|}{6} & \multicolumn{2}{|c|}{10} & \multicolumn{2}{|c|}{16} \\
\hline & $\tau$ & $n$ & $\tau$ & $n$ & $\tau$ & $n$ & $\tau$ & $n$ \\
\hline \multicolumn{9}{|c|}{ Alternating Condition } \\
\hline 20 & 4.4 & 3.5 & 4.9 & 2.9 & 5.8 & 1.8 & 5.5 & 2.8 \\
\hline 40 & 8.3 & 5.3 & 7.8 & 4.8 & 15.1 & 1.8 & 6.6 & 5.3 \\
\hline \multicolumn{9}{|c|}{ Isolated Condition } \\
\hline 20 & 3.8 & 4.5 & 3.5 & 4.5 & 8.3 & 1.5 & 5.0 & 3.4 \\
\hline 40 & 7.4 & 5.5 & 6.3 & 5.5 & 17.8 & 1.5 & 8.5 & 4.3 \\
\hline
\end{tabular}

Note-Parameter values were estimated from a least squares fit of Equation 2 to data for individual subjects in Experiment 1 and pooled across Condition 1 and Condition 3.

ent from $2.0[t(3)=-0.57, p>.05$, for alternating; $t(3)=-1.33, p>.05$, for isolated]. There were no significant differences in the values of the period when the same schedule was experienced in isolated or alternating conditions $[t(3)=-0.32, p>.05$, for FI $20 ; t(3)=$ $-0.54, p>.05$, for FI 40]. Thus, good stimulus control can isolate changes in pacemaker speed within the same experimental context.

The trend to subproportionality is consistent with the data shown in Figure 1, and it was accompanied by an increase in the criterial count, which tended to keep the modes of the distributions $(n \tau)$ close to the expected time to reinforcement. Correlated with this increase in the criterion, the coefficients of variation $\left(\mathrm{CV}=[n+1]^{-1 / 2}\right)$ decreased marginally in both the alternating condition (from 0.53 to 0.45 ) and the isolated condition (from 0.50 to 0.46 ). When the data are pooled across conditions, the decrease at the longer FI becomes significant $[t(7)=4.11, p<.05]$.

How is it that we find scalar timing in terms of the standard deviations, but a significant deviation from it in terms of the coefficients of variation? The former inference was based on the doubling of the standard deviations when the interval to be timed was doubled; the latter was based on the ratio of the standard deviations to the means of the densities. Because the densities are skewed, the means increased substantially at the FI 40 condition. If we had fixed this skew by subtracting a ramp function (Roberts, 1981), the resulting density would be approximately normal, and the coefficients of variation would be approximately constant. Thus, preprocessing of the data can convert a significant failure of the scalar hypothesis into a significant success. It is not clear, however, whether the skew that is obvious in Figure 3 is a legitimate aspect of the timing process, or rather whether it is due to responding anticipatory to the end of the trial (Church, Miller, Meck, \& Gibbon, 1991); therefore, no finer point should be put on this distinction.

\section{EXPERIMENT 2}

The results of Experiment 1 indicate that the speed of the pacemaker may be brought under the control of sig- naled local variations in the rate of reinforcement. Changes in the standard deviations of the gamma densities were proportional to changes in the interreinforcer interval (i.e., the value of the FI schedule), and that proportionality was observed both when the schedule varied within sessions (alternating condition) and when the schedule varied across sessions (isolated conditions). The changes in pacemaker speed were approximately proportional to changes in the rate of reinforcement.

In Experiment 2, we assessed the generality of these results in a quite different paradigm. Pigeons were trained on a "psychophysical choice procedure" (Stubbs, 1968), under conditions similar to those employed in Experiment 1 . In this procedure, pigeons were trained to peck the left key after a short-duration signal and the right key after a long-duration signal. Once the basic task was learned, probe trials with durations intermediate to the training stimuli were introduced (e.g., Fetterman \& Killeen, 1992). The data yielded a psychophysical function relating the probability of responding "long" as a func-
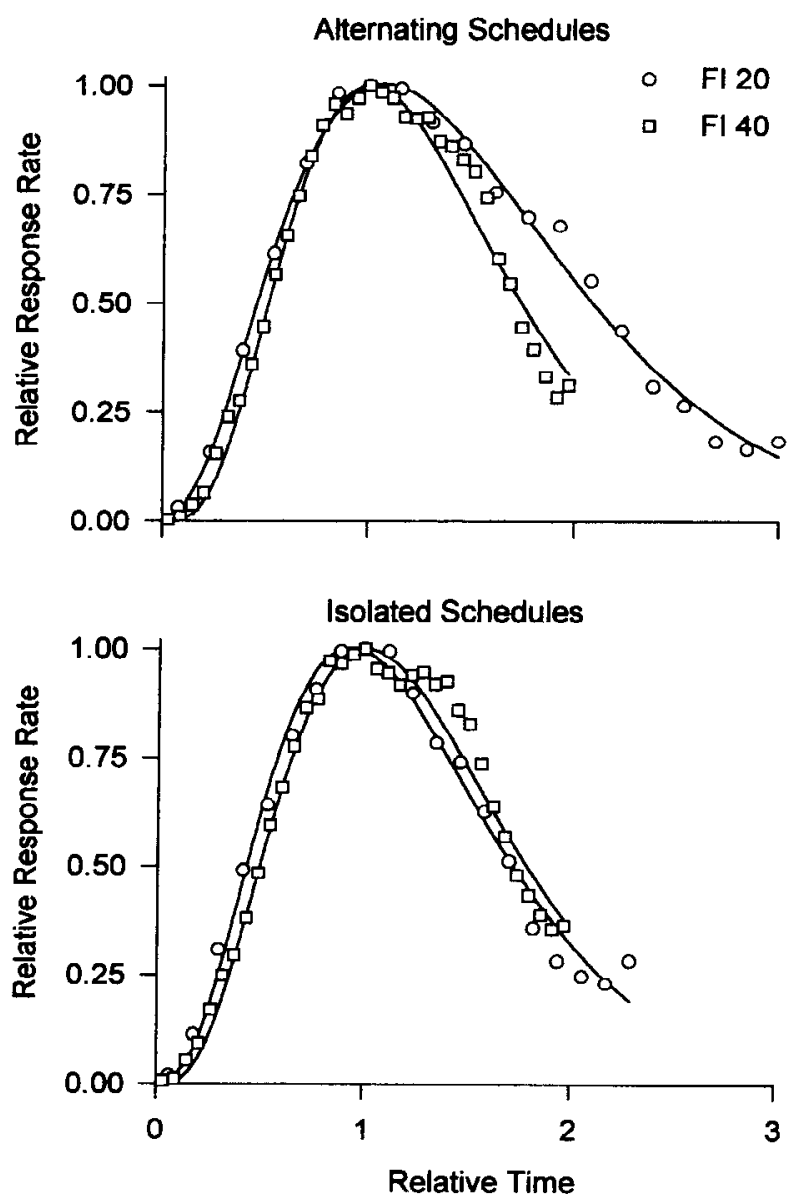

Figure 3. Response rate as a function of time since trial onset relative to trial length for average data from probe trials for the alternating (top panel) and isolated 2 (bottom panel) conditions of Experiment 1. The curves were derived from Equation 2. 
tion of the stimulus duration. The coefficient of variation of this function as an index of relative discriminability was comparable to those reported in Experiment 1.

Pigeons learned the above task with different ranges of durations. In one case, the discrimination involved short durations ( $1 \mathrm{sec}$ vs. $4 \mathrm{sec}$ ); in another, it involved longer durations ( $5 \mathrm{sec}$ vs. $20 \mathrm{sec})$. The different duration pairs were either intermixed within sessions (alternating) or presented in a successive condition (isolated), as in Experiment 1 . The main question was whether the nature of the timing context would affect relative discriminability of different temporal stimuli. If the previous results hold, the performances were expected to be primarily under the control of the local temporal context.

\section{Method}

\section{Subjects}

Four adult male pigeons (Columba livia) served as subjects. They were maintained at $80 \%$ of their free-feeding weights. The pigeons had free access to water and grit and were housed individually in a room with a 12:12-h day:night cycle, with the day cycle beginning at 7 a.m. Each pigeon was weighed before each session and was excluded from a session if its weight exceeded $10 \mathrm{~g}$ of its $80 \%$ ad-lib weight. When required, supplementary food, consisting of fortified mixed grain, was given at the end of each day.

\section{Apparatus}

The experimental enclosure was a standard BRS-LVE three-key operant chamber $(32 \mathrm{~cm}$ high $\times 34 \mathrm{~cm}$ wide $\times 34 \mathrm{~cm}$ deep). The pecking keys were accessible through $2-\mathrm{cm}$ circular openings in the work panel on the front wall, with the center of the openings spaced $6.3 \mathrm{~cm}$ apart, $25 \mathrm{~cm}$ above the chamber floor. A force of approximately $0.15 \mathrm{~N}$ was required to operate each of the keys. The feeder opening was located directly below the center response key and measured $5 \mathrm{~cm}$ on all dimensions; the bottom of the feeder opening was $10 \mathrm{~cm}$ above the chamber floor. When activated, the food hopper provided $3 \mathrm{sec}$ of access to mixed grain. White noise served to mask extraneous sounds; additional masking and ventilation were provided by an exhaust fan attached to the chamber wall. Experimental events were scheduled and recorded by an IBM PC.

\section{Procedure}

Basic training. The pigeons were trained to eat from a raised food hopper. They were then autoshaped to peck at an amber key that was randomly varied from left to center to right positions on the front wall. This procedure produced reliable pecking on all keys by all birds within three sessions

Experimental training. All pigeons were then trained on a temporal discrimination task with the following characteristics: Trials began with the illumination of the center keylight with red or green light. The keylight remained on for some duration and then went off independently of behavior; the offset of the center keylight was accompanied by the onset of lights behind the left and right keys. The colors of the side keylights were the same as the center keylight. A peck to one side key was correct after short durations of the center keylight, and a peck to the alternative side key was correct following long durations of the center keylight. The correct key location after short and long durations was counterbalanced across birds. A noncorrection procedure was used. Correct responses produced reinforcement followed by a $15-\mathrm{sec}$ ITI. Incorrect responses produced the ITI directly. Sessions ended after 100 trials.

There were two sets of stimuli used during training: a short set ( $1 \mathrm{sec}$ and $4 \mathrm{sec}$ ) and a long set $(5 \mathrm{sec}$ and $20 \mathrm{sec}$ ). Red keylights (center and side keys) signified the short set, and green keylights signified the long set. In both cases, the subject's task was to peck
Table 3

\begin{tabular}{lcccc}
\multirow{2}{*}{$\begin{array}{c}\text { Number of Sessions and Order of Exposure for Each Pigeon } \\
\text { for Each Condition of Experiment 2 }\end{array}$} \\
\cline { 2 - 5 } & \multicolumn{4}{c}{ Pigeon } \\
Condition & 38 & 47 & 52 & 73 \\
\hline Alternating & $40(1)$ & $48(1)$ & $37(3)$ & $39(3)$ \\
Isolated & & & & \\
$1-4 \mathrm{sec}$ & $20(2)$ & $20(3)$ & $31(1)$ & $23(2)$ \\
$5-20 \mathrm{sec}$ & $20(3)$ & $22(2)$ & $23(2)$ & $29(1)$ \\
\hline
\end{tabular}

Note-The numbers in parentheses indicate the order of exposure to the three conditions of Experiment 2.

one choice key after the shorter duration of a set, and the alternative choice key after the longer duration of that set. The choice keyduration assignments were consistent across test ranges, such that, for instance, if the left key was correct after 1 sec of red (short set), it was also correct after $5 \mathrm{sec}$ of green (long set).

The major manipulation involved the manner in which the pigeons experienced the different sets of durations. In the alternating condition, the birds experienced both sets in each session, with the set cued by the color of the center and side keylights, as described above. Thus, sessions consisted of red-key and green-key trials, and the center-key durations and choice-key contingencies associated with the different key colors. In the isolated condition, a single set was tested for an extended number of sessions, followed by exposure to a second set for a similar number of sessions. Two birds experienced the alternating condition first, and 2 experienced the isolated condition first. When the birds were tested in the isolated condition, the order of exposure to the different sets was counterbalanced across subjects. Table 3 provides information on the various conditions and the order in which each pigeon experienced them.

Experimental testing. The pigeons were tested with probe stimuli intermediate to the training durations under each set, in both the alternating and the isolated conditions. Three probe durations were used for each set: 1.4,2.0, and $2.8 \mathrm{sec}$ (short set), and 7.1, 10.0, and $14.1 \mathrm{sec}$ (long set). The key colors associated with probe durations were the same as those associated with the training durations (i.e., red for short probes, and green for long probes). Probe durations were presented on half of the trials during each test session, and choices on probe duration trials were not reinforced. Probe trials were randomly intermixed with training duration trials on which correct choice responses were reinforced; thus, the nominal probability of reinforcement for choice responses over the entire session was .50 . Probe sessions alternated with nonprobe sessions during which only the training durations were used; during these sessions, the scheduled probability of reinforcement for correct choices was kept at .50 , by omitting half the scheduled reinforcers. Reinforcement was arranged according to the method of Stubbs (1976; see Fetterman, 1995, for details).

\section{Data Analysis}

It is traditional to fit a cumulative normal distribution to the psychometric functions - or, more conveniently, the logistic distribution that closely approximates the normal. The logistic distribution gives the probability of responding on the "long" key as a function of the stimulus duration $(t)$ as

$$
p(\text { "long" } \mid t)=\left(1+e^{-k z}\right)^{-1},
$$

where

$$
k=\pi / \sqrt{3} \cong 1.814 \text {, }
$$

and

$$
z=\frac{t-\mu}{\sigma}
$$




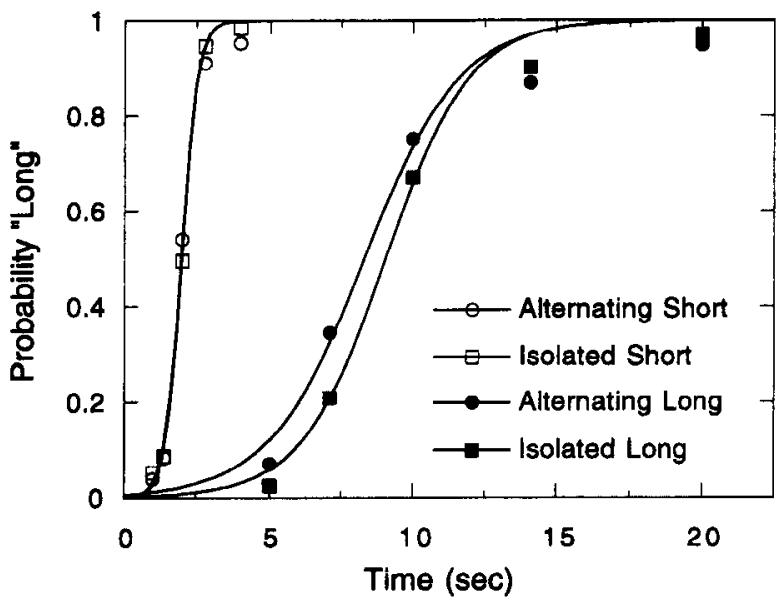

Figure 4. The psychometric functions from Experiment 2, with the open symbols coming from the short set, and the filled symbols coming from the long set; the circles indicate the alternating conditions, and the squares indicate the isolated conditions. Note that the subjects were under strong control by the set stimulus and showed only minor differences as a function of the alternating/isolated condition. The curves are the best-fitting versions of Equation 5.

Fitting Equation 5 to the data by minimizing the squared deviations yields the mean $(\mu)$ and standard deviation $(\sigma)$ directly; $n$ and $\tau$ may be found by rearranging Equations 3 and 4 .

\section{Results and Discussion}

Figure 4 shows the psychometric functions with associated logistic distributions. The fit of Equation 5 to the data is less than perfect for reasons we now understand (Killeen et al., 1997; see Table 4 for individual parameters), but adequate for the present analysis. The first thing to note is that, whether presented alternating with one another or isolated, the performances on the short sets (unfilled circles and squares) were identical. The effect of having a longer discrimination in the same context had no effect on performance. There was an apparent effect on the psychometric functions for the long set, with the mean from the alternating condition slightly less than that for the isolated condition; however, that difference was not significant $[t(3)=-0.86, p>.05]$.

There was no significant difference among the coefficients of variation $[F(3,12)=0.58]$, indicating that Weber's law holds for these data. The coefficients were half the size of those found in Experiment $1(0.27$ vs. 0.48) $[t(30)=6.9, p<.05]$, showing that this paradigm forces a finer discrimination, as one might expect. These coefficients replicate those found in a comparable experiment (Fetterman \& Killeen, 1992; .22) within the 95\% confidence interval of the present data (.22-.32).

Overall, the difference between short and long sets was brought about by a difference in the speed of the pacemaker $[t(7)=3.427, p<.05]$. Pacemaker speeds were much faster in Experiment 2 ( $\tau \mathrm{s}$ of .12 and $.21 \mathrm{sec}$ in the two conditions), suggesting that qualitatively different pacemakers might have been engaged by the two tasks.

These results provide a systematic replication of those from Experiment 1: Strong stimulus control may be established within an experimental context by signaling different interval durations.

\section{GENERAL DISCUSSION}

These results show that when the different color/location stimuli were alternated within sessions, each stimulus functioned as a distinctive context associated with a particular rate of reinforcement. At the behavioral level, there was very little difference within experiments between the timing engendered by the alternating schedules of reinforcement and the timing observed when the schedules were presented in isolation (Figures 2-4). Timing obeyed Weber's law (Experiment 2) or approximated it (Experiment 1). Had the stimuli been less distinctive we may have found less differentiation of the pacemaker rate due to greater generalization of the reinforcement context between key colors.

These results may be contrasted with those of Fetterman and Killeen (1995), who used a design in which each of three intervals (e.g., $8 \mathrm{sec}, 16 \mathrm{sec}, 32 \mathrm{sec}$ ) was associated with a different response key. All of the keys were illuminated, but reinforcement was primed on only one of the keys on each trial, and the timing was concurrentthat is, it was a "mixed" schedule of reinforcement (Ferster \& Skinner, 1957). The timing of switches between

Table 4

Estimates of the Mean, $\mu$, Standard Deviation $\sigma$, Pacemaker Period, $\tau$, and Criterion, $n$

\begin{tabular}{|c|c|c|c|c|}
\hline & \multicolumn{4}{|c|}{ Pigeon } \\
\hline & 38 & 47 & 52 & 73 \\
\hline \multicolumn{5}{|c|}{ Alternating (1-4 sec) Condition } \\
\hline$\mu$ & 1.88 & 1.96 & 1.83 & 2.22 \\
\hline$\sigma$ & .374 & .598 & .358 & .454 \\
\hline$\tau$ & .215 & .187 & .094 & .105 \\
\hline$n$ & 9.15 & 10.5 & 19.3 & 21.2 \\
\hline \multicolumn{5}{|c|}{ Alternating $(5-20 \mathrm{sec})$ Condition } \\
\hline$\mu$ & 9.0 & 7.27 & 7.89 & 9.45 \\
\hline$\sigma$ & 2.48 & 2.28 & 1.63 & 4.21 \\
\hline$\tau$ & 479 & 1.04 & .343 & 1.76 \\
\hline$n$ & 18.8 & 6.91 & 22.9 & 5.41 \\
\hline \multicolumn{5}{|c|}{ Isolated ( $1-4 \mathrm{sec})$ Condition } \\
\hline$\mu$ & 2.28 & 2.17 & 1.91 & 1.68 \\
\hline$\sigma$ & .49 & .394 & .420 & .380 \\
\hline$\tau$ & .113 & .072 & .086 & .081 \\
\hline$n$ & 19.9 & 30.0 & 22.0 & 20.7 \\
\hline \multicolumn{5}{|c|}{ Isolated $(5-20 \mathrm{sec})$ Condition } \\
\hline$\mu$ & 8.89 & 8.96 & 10.1 & 8.31 \\
\hline$\sigma$ & 2.34 & 1.5 & 2.39 & 2.81 \\
\hline$\tau$ & .593 & .277 & .537 & 1.34 \\
\hline$n$ & 14.9 & 32.1 & 18.7 & 6.28 \\
\hline
\end{tabular}

Note-Parameter values were estimated from a least squares fit of Equation 2 to data for individual subjects in Experiment 2. 
the keys was Poisson, as predicted by BeT, not scalar, as predicted by SET. When the interval requirements were varied between conditions (e.g., $4 \mathrm{sec}, 8 \mathrm{sec}, 16 \mathrm{sec}$ in one condition, and $8 \mathrm{sec}, 16 \mathrm{sec}, 32 \mathrm{sec}$ in another condition, similar to the isolated conditions of the present study), comparisons made across conditions followed Weber's law, as was the case in the present study. Thus, when an organism must time several intervals concurrently, we expect that to be accomplished by the use of multiple criteria for the counts from a constant pacemaker, yielding Poisson timing. When different contexts permit the use of different pacemakers, scalar timing is expected and observed.

This picture is clouded by an experiment of Leak and Gibbon (1995), who trained pigeons on a task very similar to the one just described. The birds experienced two, and sometimes three, intervals within sessions. Under this simultaneous timing task, the birds' behavior was more consistent with Weber timing than with Poisson timing. This was true for both variability in start times and variability in peak times. In their experiment, all responding was on the same key, and timing of the different intervals was inferred from a sophisticated analysis of changes in response rates. In order to measure these changes, the intervals had to be separated by fourfold to sixfold ratios (e.g., mixed [FI 60, FI 240]). Their summary figures of responding in these situations show response rate increasing to a sharp early peak and then decreasing to a lower, flatter peak around the time of the second interval, and still lower and flatter to the third interval. These are discriminably different epochs, marked by lowered vigor of responding at the longer intervals. The animals are clearly less aroused at the end of the long intervals. It is not unreasonable to expect some slowing of their pacemaker under these circumstances. Passage of time can serve as a signal of lowered rate of reinforcement in just the same manner as a change of key color. To the extent the pacemaker slowed along with response rates, we would expect to see Poisson timing blend into Weber timing. Indeed, such slowing may be a part of any timing experiment, but when intervals are closer together, the results are not discriminable from Poisson timing.

$\mathrm{BeT}$ assumes that the speed of the clock is driven by processes such as those represented in Equation 1. When animals are called upon to time intervals, a criterial number of counts is shaped by the extant contingencies of reinforcement. There is a relatively flat optimum on either $n$ or $\tau$ by itself, as tradeoffs between them can leave responding near its peak while keeping the variance around that peak small.

Experiment 1 demonstrated Weber' $s$ law in a context where changes in $\tau$ alone were insufficient to bring it about. If changes in $\tau$ are less than proportional to the interval length, as was the case in Figure 1 and Experiment 1 , then $n$ must increase with the interval in order to keep the distribution of responding centered near the expected time of reinforcement. Because the clock did not slow down by half when going to the FI 40 , the criterial number of counts increased to keep $n \tau \cong T$.

It is not necessary to think that subjects are attempting to place their peak rates in any particular location; it is just that the equilibrium processes of reinforcement select criterial values of $n$ that station maximal responding around the time of food. Those count numbers are maximally strengthened for which the associated state is the best predictor of reinforcement. A more complete version of BeT, such as that drawn by Machado (1997), derives this equilibrium as a natural theorem.

These are minor variants of the story whose major theme is that (1) pacemaker speed varies with rate of reinforcement and can come under stimulus control, (2) the number of criterial counts in temporal production (Experiment 1) and categorization (Experiment 2) are then adjusted by reinforcement contingencies to keep responding maximal around the time of reinforcement (Experiment 1) and to keep discrimination relatively unbiased (Experiment 2), and (3) if the speed of the pacemaker is not correlated with the changes in interval length, compensations by adjusting $n$ will cause deviations from Weber's law. In the extreme case of a constant pacemaker, $n$ is forced proportional to $t$, leading to Poisson timing.

There is nothing in the behavioral theory of timing that requires use of a single pacemaker with variable speeds. Pigeons often make categorical judgments of brief stimuli (Experiment 2) by oscillating in front of the short key a couple of times and then moving to another part of the chamber (Fetterman, Killeen, \& Hall, in press). Here, their body is the pendulum/pacemaker; the short-latency high-frequency physical movements are supported by high rates of reinforcement (which engender high levels of arousal that can sustain such performances). Different behaviors will mediate discrimination of longer intervals, as in Experiment 1, where the more desultory actions of postreinforcement area-restricted search may be the mediators. If, during some intervals, the critical behaviors are absent (Fetterman et al., in press; Reid, Bacha, \& Moran, 1993), temporal judgments will fall to chance.

Finally, the degrees of freedom inherent in this model are underutilized: BeT allows error in the counter, but, for simplicity, has kept that to zero, thus permitting the use of the simple Poisson process and the associated gamma distribution. The pacemaker is likely to be more accurate than a Poisson emitter, but that will primarily affect inferences about parameter values, and not the qualitative aspects of the theory. Weber-like timing is not a threat to BeT; it is derivable either from shifts in the speed of the pacemaker or from that and proportional error in the counter, the latter of which we defer invoking until necessary (cf. Killeen \& Weiss, 1987). We have assumed that conditioning of the response to the appropriate Poisson state is perfect, thus obviating the need for "comparison with reference memory" found in other theories (temporal judgments are all-or-none given the states; it is the variability of the states that makes judgments prob- 
abilistic). As we allow imperfection in the counter (i.e., imperfect conditioning of the states; Machado, 1997), that additional source of error both will come closer to a realistic description and will blunt the distinction between theories. It is, in the end, a qualitative issue - the behavioral mediation of timing - and not a quantitative one that distinguishes these two very quantitative models of the timing process.

\section{REFERENCES}

Allan, L. G., \& Kristofferson, A. B. (1974). Judgments about the duration of brief stimuli. Perception \& Psychophysics, 15, 434-440.

Bizo, L. A., \& WhiTE, K. G. (1994a). The behavioral theory of timing: Reinforcer rate determines pacemaker rate. Journal of the Experimental Analysis of Behavior, 61, 19-34.

Bizo, L. A.. \& White, K. G. (1994b). Pacemaker rate in the behavioral theory of timing. Journal of Experimental Psychology: Animal Behavior Processes, 20, 1-14

Bizo, L. A., \& WhITE, K. G. (1997). Timing with controlled reinforcer density: Implications for models of timing. Journal of Experimental Psychology: Animal Behavior Processes, 23, 44-55.

CAtania, A. C. (1970). Reinforcement schedules and psychophysical judgments: A study of some temporal properties of behavior. In W. N Schoenfeld (Ed.), The theory of reinforcement schedules (pp. 1-42). New York: Appleton-Century-Crofts.

Church, R. M., Miller, K. D., Meck, W. H., \& Gibbon, J. (1991). Symmetrical and asymmetrical sources of variance in temporal generalization. Animal Learning \& Behavior, 19, 207-214.

Ferster, C. B., \& Skinner, B. F. (1957). Schedules of reinforcement. New York: Appleton-Century-Crofts.

Fetterman, J. G. (1995). The psychophysics of remembered duration. Animal Learning \& Behavior, 23, 49-62.

Fetterman, J, G., \& Killeen, P. R. (1991). Adjusting the pacemaker. Learning \& Motivation, 22, 226-252.

Fetterman, J. G., \& Killeen, P. R. (1992). Time discrimination in Columba livia and Homo sapiens. Journal of Experimental Psychology: Animal Behavior Processes, 18, 80-94.

Fetterman, J. G., \& Killeen, P. R. (1995). Categorical scaling of time: Implications for clock-counter models. Journal of Experimental Psychology: Animal Behavior Processes, 21, 43-63.

Fetterman, J. G., KilleEn, P. R., \& Hall, S. (in press). Watching the clock. Behavioural Processes.

GiBBon, J. (1977). Scalar expectancy theory and Weber's law in animal timing. Psychological Review, 84, 279-325.

GibBON, J. (1986). The structure of subjective time: How time flies. In G. H. Bower (Ed.), The psychology of learning and motivation (Vol. 20 , pp. 105-135). New York: Academic Press.

GibBon, J. (1992). Ubiquity of scalar timing with a Poisson clock. Journal of Mathematical Psychology, 36, 283-293.

GibBon, J. (1995). Dynamics of time matching: Arousal makes better seem worse. Psychonomic Bulletin \& Review, 2, 208-215.

Gibbon, J., \& CHURCH, R. M. (1984). Sources of variance in an information processing theory of timing. In H. L. Roitblatt, T. G. Bever, \& H. S. Terrace (Eds.), Animal cognition (pp. 465-488). Hillsdale, NJ: Erlbaum.

Haight, P. A., \& KilLeEn, P. R. (1991). Adjunctive behavior in multiple schedules of reinforcement. Animal Learning \& Behavior, 19, 257-263.

HERRNSTEIN, R. J. (1970). On the law of effect. Journal of the Experimental Analysis of Behavior, 13, 243-266.
KilleEn, P. R. (1975). On the temporal control of behavior. Psychological Review, 82, 89-115.

KILLEEN, P. R. (1979). Arousal: Its genesis, modulation, and extinction. In M. D. Zeiler \& P. Harzem (Eds.), Advances in the analysis of behavior: Vol. 1, Reinforcement and the organization of behavior (pp. 31-78). New York: Elsevier.

Killeen, P. R., \& Fetterman, J. G. (1988). A behavioral theory of timing. Psychological Review, 95, 274-295.

Killeen, P. R., \& FetTerman, J. G. (1993). Behavioral theory of timing: Transition analyses. Journal of the Experimental Analysis of Behavior, 59, 411-422.

Killeen, P. R., Fetterman, J. G., \& Bizo, L. A. (1997). Time's causes. In C. M. Bradshaw \& E. Szabadi (Eds.), Time and behaviour: Psychological and neurobiological analyses (pp. 79-131). Amsterdam: Elsevier.

KILLEEN, P. R., \& WeISS, N. (1987). Optimal timing and the Weber function. Psychological Review, 94, 455-468.

LEAK, T. M., \& GiBbON, J. (1995). Simultaneous timing of multiple intervals: Implications of the scalar property. Journal of Experimental Psychology: Animal Behavior Processes, 21, 3-19.

MACEWEN, D., \& KILLEEN, P. [R.] (1991). The effects of rate and amount of reinforcement on the speed of the pacemaker in pigeons' timing behavior. Animal Learning \& Behavior, 19, 164-170.

MACHADO, A. (1997). Learning the temporal dynamics of behavior. Psychological Review, 104, 241-265.

Meck, W. [H.] (1983), Selective adjustment of the speed of internal clock and memory processes. Journal of Experimental Psychology: Animal Behavior Processes, 9, 171-201

MECK, W. H., \& CHURCH, R. M. (1987). Nutrients that modify the speed of internal clock and memory storage processes. Behavioral Neuroscience, 101, 465-475.

Morgan, L., Killeen, P. R., \& Fetterman, J. G. (1993). Changing rates of reinforcement perturbs the flow of time. Behavioural Processes, 30, 259-272.

Penton-Voak, I. S., Edwards, H., Percival, A., \& Wearden, J. H. (1996). Speeding-up an internal clock in humans: Effects of click trains on subjective duration. Journal of Experimental Psychology: Animal Behavior Processes, 22, 307-320.

ReID, A. K., BaCha, G., \& MoRan, C. (1993). The temporal organization of behavior on periodic food schedules. Journal of the Experimental Analysis of Behavior, 59, 1-27.

ROBERTS, S. (1981). Isolation of an internal clock. Journal of Experimental Psychology: Animal Behavioral Processes, 7, 242-268.

ROBERTS, S., \& HOLDER, M. D. (1985). Effect of classical conditioning on an internal clock. Journal of Experimental Psychology: Animal Behavior Processes, 12, 194-214.

ShurTlefF, D., Raslear, T. G., \& Simmons, L. (1990). Circadian variations in time perception in rats. Physiology \& Behavior, 47, 931-939.

StubBs, [D.] A. (1968). The discrimination of stimulus duration by pigeons. Journal of the Experimental Analysis of Behavior, 11, 223-238.

STUBBS, D. A. (1976). Response bias and the discrimination of stimulus durations. Journal of the Experimental Analysis of Behavior, 25, 243-250.

Wearden, J. H., \& Penton-Voak, I. S. (1995). Feeling the heat: Body temperature and the rate of subjective time, revisited. Quarterly Journal of Experimental Psychology, 48B, 129-141.

WILKIE, D. M., \& SYMONS, L. A. (1988). Effects of intertrial reinforcers on rats' timing behavior. Behavioral Processes, 17, 229-238.

(Manuscript received August 27, 1997; revision accepted for publication July 22, 1998.) 